\title{
ПЕРЕРАБОТКА ЗЕРНА В ЗОЛОТООРДЫНСКОМ ГОРОДЕ МАДЖАР 1
}

\author{
(C) 2021 г. Ю.Д. Обухов
}

В статье предлагается на обсуждение тематика переработки зерна и развитие мукомольного производства в городах Золотой Орды. Рассматривается потребность в результатах этого производства среди кочевого населения, путешествующих купцов, послов и миссионеров. Следы переработки зерна приводятся как на примере археологических исследований города Маджар и материалов, полученных при археологических работах в городе Азаке, так и на основании средневековые письменных источников.

Ключевые слова: археология, Маджар, Азак, Золотая Орда, жёрнов, мука, сухари, мукомольное производство.

\section{GRAIN PROCESSING IN THE GOLDEN HORDE CITY OF MADZHAR²}

\section{Yu. D. Obukhov}

The article proposes to discuss the issue of grain processing and the development of flour milling in the cities of the Golden Horde. Using the example of the archaeological research of the city of Madzhar and the materials obtained during the archaeological work in the city of Azak, as well as drawing on medieval sources, the need for this production among the nomadic population, traveling merchants, ambassadors and missionaries is also considered.

Keywords: archaeology, Madzhar, Azak, Golden Horde, millstone, flour, crackers, flour milling.

К середине XIII в. территория Северного Кавказа находилась под властью Золотой Орды. Местом для административного центра этого региона было выбрано Прикумье, имеющее благоприятные природные условия как для развития кочевого скотоводства, так и для оседлого земледелия, а также обилие сырьевых ресурсов для питания человека и различных ремесел. Регион обладал достаточными водными ресурсами: река Кума с ближайшими притоками - реками Томузловкой и Буйволой. В пойме реки Кумы имелось много плодородной земли для развития сельского хозяйства; по обеим сторонам долины простирались обширные степные пространства, пригодные для развития коневодства и скотоводства. Все это и стало основой для возведения в середине XIII столетия на берегах реки Кумы и её притока р. Буйволы центра Золотой Орды на Северном Кавказе - города Маджар.

Наивысшего рассвета Маджар достиг, как, впрочем, и само государство Золотая Орда, при ханах Узбеке и Джанибеке (1318-1357 гг.). Однако после смерти последнего начался стремительный распад государства, междоусобицы правителей, изменение направления караванных путей обусловили постепенное запустение города и, как следствие, его сельскохозяйственной округи.

Письменные источники XIV в. и археологические данные свидетельствуют о возделывании здесь разнообразных сельскохозяйственных культур. В записках арабского путешественника Ибн-Баттуты, посетившего Маджары летом 1334 г., в пору его расцвета, говорится о Маджаре как о «большом, одном из лучших тюркских городов, на большой реке, с садами и обильными плодами» (Тизенгаузен, 1884, с. 287).

Во время производства археологических работ и сбора подъёмного материала на территории городища Маджары находят жернова из вязкого, твердого песчаника, как для ручного помола зерна (рис. 1), не превышающие полуметра в диаметре, так и крупные - более метра - приводимые в движение живою силою для выработки большого объёма муки.

В разное время автором после плантажной вспашки на городище были найдены и сохраняются в формирующемся фонде Маджарского археологического музея два крупных фрагментированных верхних жёрнова (бегуна) как тщательной (рис. 2) отделки, так и весьма посредственной (рис. 3), но объединенных

Работа выполнена в рамках проекта РФФИ № 20-39-90023 «Золотоордынский город Маджар и его возможная округа - Верхний Маджар и Нижний Маджар, входившие в систему Маджарской агломерации».

2 The work was carried out within the framework of the RFBR project No. 20-39-90023 "The Golden Horde City of Madjar and its Possible Districts - Upper Madjar and Lower Madjar, Part of the Madjar Agglomeration System" 

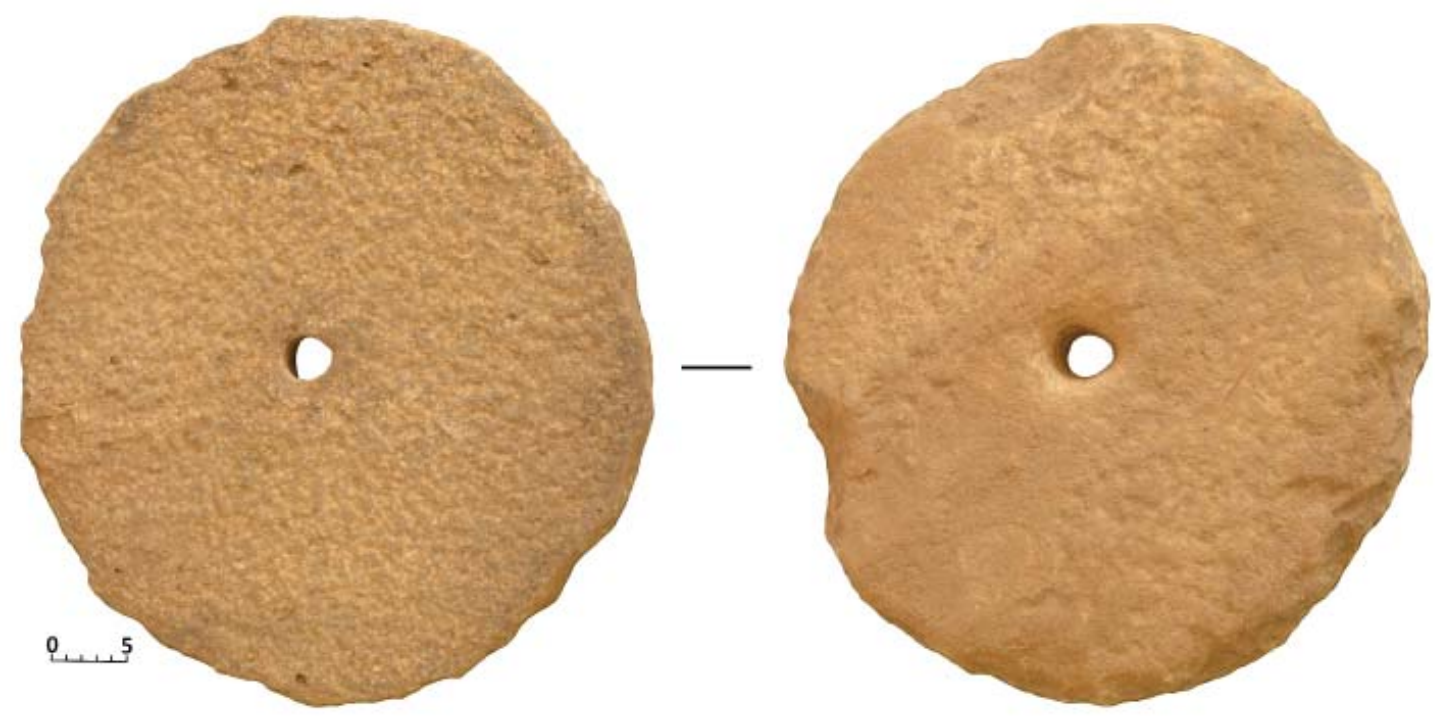

Рис. 1. Ручной жёрнов. Городище Маджары. Сборы Ю.Обухова Fig. 1. Manual millstone. Madjary Settlement. Collected by Yu. Obukhov
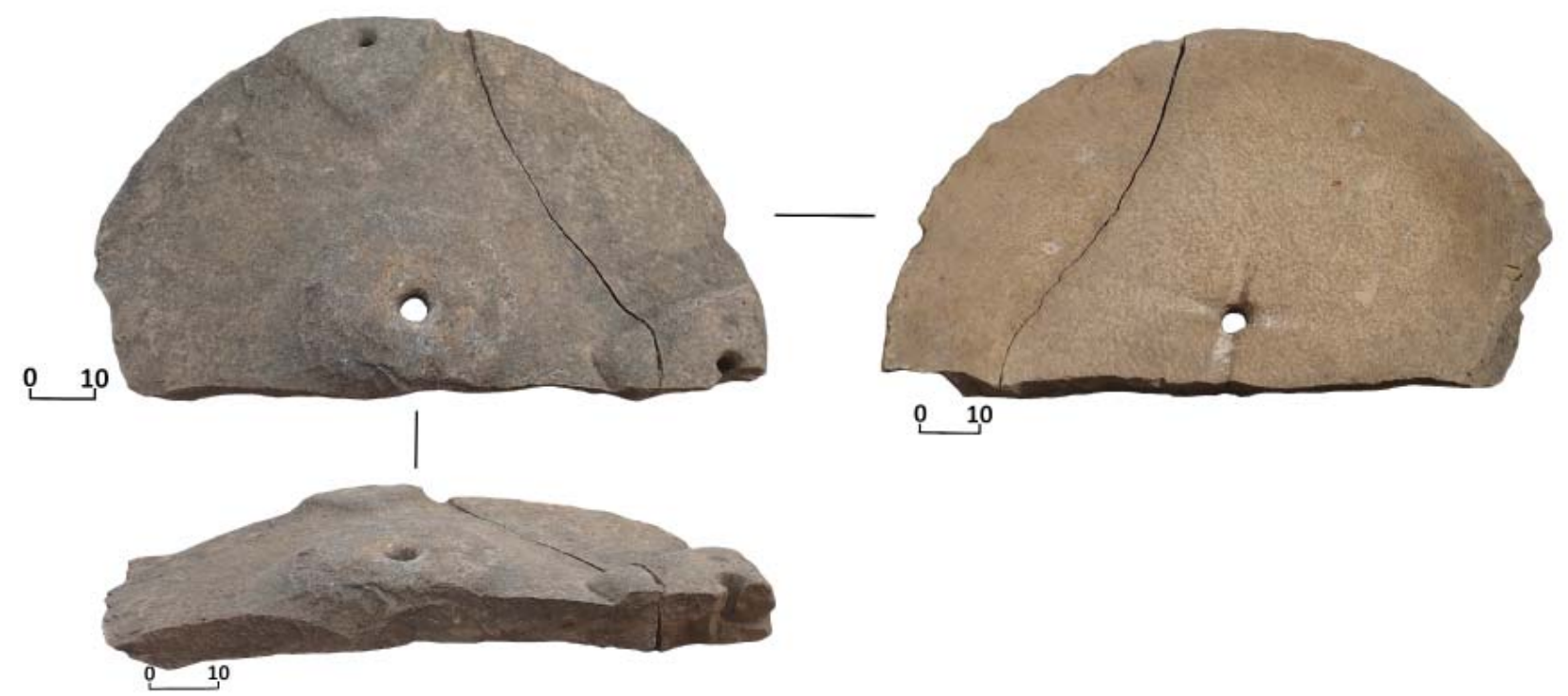

Рис. 2. Большой жернов «Бегун» тщательной отделки, приводимый в движение живою силою.

Городище Маджары. Сборы Ю. Обухова

Fig. 2. Large "Runner" millstone, of thorough finish, set in motion by living force. Madjary Settlement. Collected by Yu. Obukhov

общими признаками, а именно расположенными в верхней части тремя технологическими глухими отверстиями, в виде колена выходящими в боковую поверхность жернова для крепления рычагов либо продевания верёвок. O находке таких же жерновов при археологическом исследовании на Маджарском городище в 1907 г. писал в своём отчете В.А. Городцов.

Исследуя городище и прилегающие окрестности с целью определения мест раскопок, Городцов опрашивал жителей близлежащих сёл и города Святого Креста о находках древних предметов, найденных на Маджаре, а также осматривал и фиксировал эти находки, среди которых в том числе были и жернова. В своём отчете Василий Алексеевич приводит описание семи больших жерновов, размеры которых были от 1 аршина 4 вершков до 1 аршина $12 \frac{1}{2}$ вершков, а также одного большого, еще не отделанного жернового камня. Во время производства археологических работ им также обнаружены, помимо фрагментов маленьких жерновков, «...круглый каменный каток правильной цилиндрической формы; длина его достигала 1 аршина 6 вершков, а диаметр - 6 вершков» для обмолота зерна и «большой жернов, диаметр его равнялся 1 1/4 аршина, а толщина приблизительно $1 \frac{1}{2}$ вершка ${ }^{1} \gg($ Городцов, 1911, с. 176-182). 


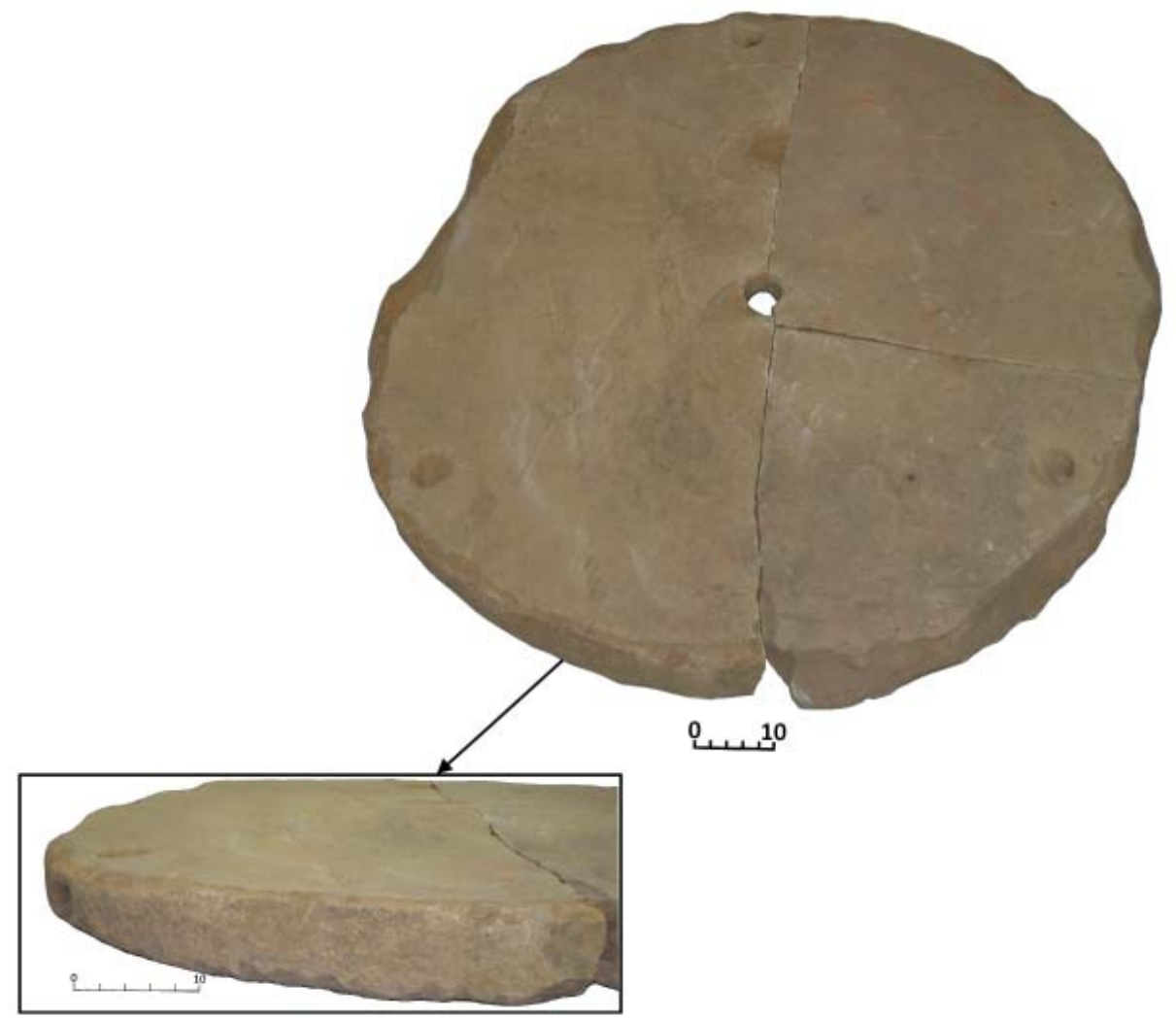

Рис. 3. Большой жернов «Бегун» посредственной отделки, приводимый в движение живою силою. Городище Маджары. Сборы Ю. Обухова

Fig. 3. Large "Runner" millstone of mediocre finish, set in motion by living force. Madjary Settlement. Collected by Yu. Obukhov

Всё это служит свидетельством переработки в Маджаре зерна как в домашних условиях, так и существования мукомолен для «промышленного» производства муки, которое требовало достаточного количества зерна, производимого, вероятно, в сельскохозяйственной округе, хотя полностью исключать импорт мы тоже не можем. Все жернова приводились в движение живой силой. Нижний жёрнов (постав) устанавливался стационарно и был, вероятно, массивен (рис. 4). На сегодняшний день, на городище не обнаружен ни один целый экземпляр. Самыми массовыми находками являются подвижные, производящие непосредственное перемалывание, верхние жернова (бегуны) и их фрагменты.

Находки ручных жерновов, а также их производство отмечены на золотоордынских памятниках Поволжья (Пигарев, 2009. с. 65; Недашковский, 2009. с. 95).

В то же время крупные жернова встречаются не на всех золотоордынских памятниках, и их находки могут свидетельствовать о наличии мукомольного производства в данных городских центрах, обусловленного необходимостью большого производства муки.
Большому городу требовалось и большое количество производимой сельскохозяйственной продукции, в том числе зерновых культур и производимой из них муки. В пробах с территории торгово-ремесленного квартала городища Маджары выделены семена проса двух видов, мягкой пшеницы и ячменя (Бабенко, Сергеев, 2019, с. 166-167). И если зерновые культуры производились в сельской округе либо были предметом импорта, то производимые из них мука и крупы были результатом переработки непосредственно на месте, то есть в городе, как для индивидуальных нужд, так и для продажи, поскольку большие мельничные комплексы подразумевают большее производство муки, выходящее за рамки индивидуального домашнего потребления. Слабая изученность Маджар не позволяет на сегодняшний день говорить о наличии в городе каких-либо других мельниц, приводимых в движение энергией альтернативной живой силе, например, ветряных мельниц башенного типа с поворотным шатром, какие были в Азаке (Минаев, 2018, с. 128-129).

Очевидно, что потребность в муке была вызвана не только спросом проживающего в городе населения, а также кочевников, в пита- 


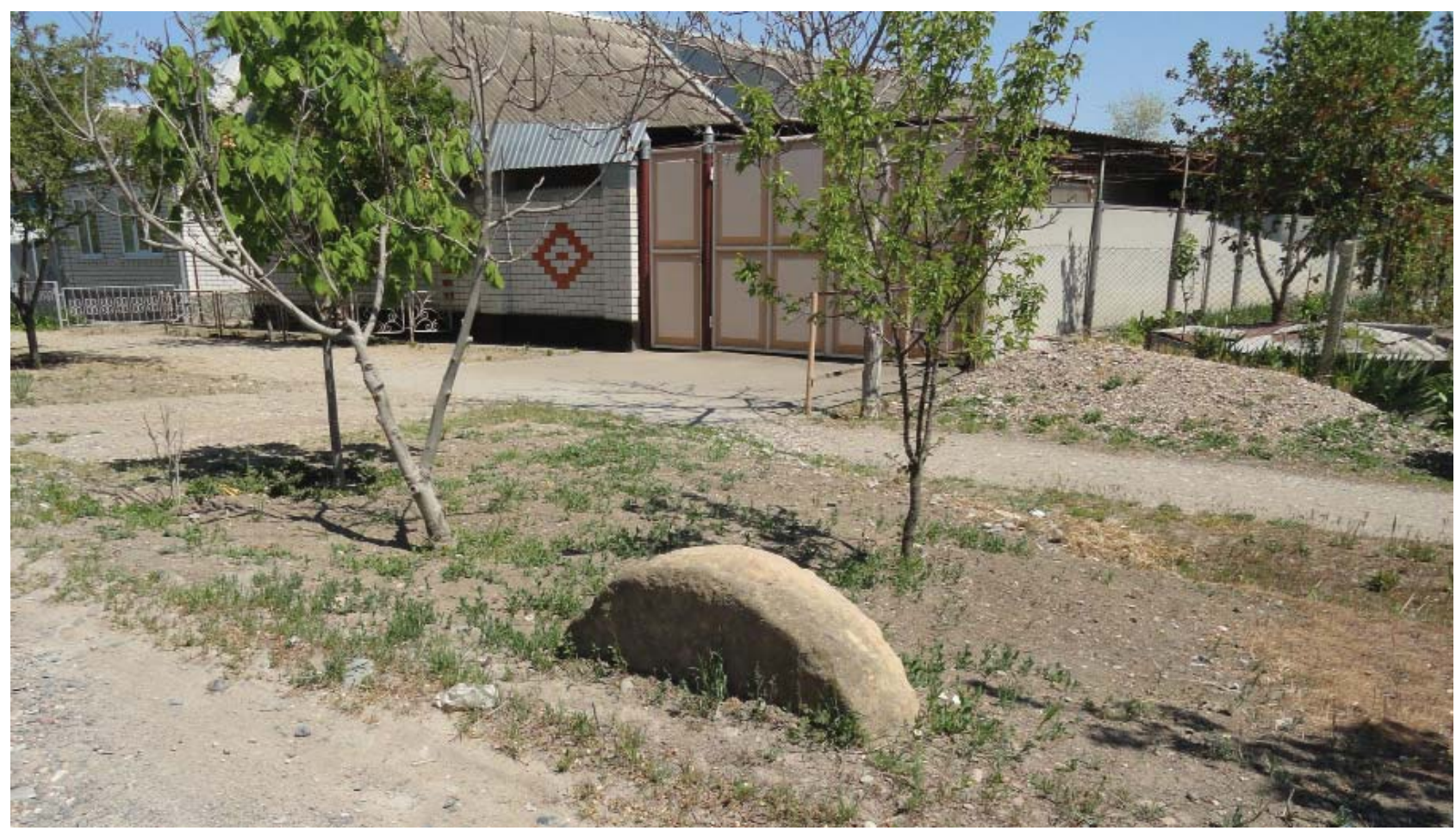

Рис. 4. Вероятный «Постав» большого жёрнова. Село Прасковея Будённовский муниципальный округ 2019 г.

Fig. 4. Probable "foundation" of a large millstone. Praskoveya village of the Budennovsky municipal district, 2019

нии которых растительная пища, мука и крупы занимали определённое место (Пигарев, 2009, c. 63), но и другой категории потребителей.

Знакомясь со средневековыми источниками середины XIII-XV в., мы находим подтверждения потребности в муке, крупах и сухарях (хлебе) также передвигающихся по территории Золотой Орды путешественников и купцов.

О необходимости брать с собой в дальний путь сухари упоминал Вильгельм де Рубрук: «По совету купиов, я привёз с собою из Константинополя, в качестве подарков главным начальникам, плодов, мускатного вина и вкуснылх сухарей (biscoctum)» (Рубрук, 1911 , с. 68). О количестве сухарей, взятых с собой Рубруком, мы можем судить по его свидетельствам о раздаче их в качестве подарков и их наличию, когда другие запасы были уже на исходе: «Он спросил, что несём мы его господину. Мы взяли бутылкку вина, наполнили корзину сухарями и блюдо яблоками и другими фруктами... В пищу нам давали только коровье молоко, очень кислое и вонючее. Вино было у нас уже на исходе... Если бы у нас не было сухарей, которые мы имели, и милости божией, мы, наверное, умерли бы от голода» (Рубрук, 1911, с. 82, 84).

Необходимость в больших запасах сухарей (хлеба) была обусловлена для европейских путешественников в середине XIII в. отсут- ствием возможности их приобретения в Золотой Орде. Об этом свидетельствует Плано Карпини: «Хлеба у них нет, равно как зелени и овощей и ничего другого кроме мяса...» (Карпини, 1911, с. 14). Его сведения об отсутствии хлеба подтверждает и марокканский путешественник Абу-Абдаллах Мухаммед Ибн-Батута: «Тюрки эти не едят ни хлеба, ни плотной пищи, а приготовляют еду из какогото (водящегося) у них (проса)» (Тизенгаузен, 1884 , c. 283).

С развитием торговли и транспортных коммуникаций, вероятно, меняется спрос и предложение на различные товары, в том числе и продовольствие.

Итальянский купец Франческо Бальдуччи Пеголотти, свершив путешествие в восточные страны, написал труд «Руководство по торговле», в котором, в частности, указывал: «Путешествуя из Tаны в Джсинтархан, нужно иметь провизии на 25 дней, то есть муку и солённую рыбу, так как мяса вы найдёте в изобилии на всём пути» (Аталиков, 2010, c. 10).

Другой итальянский путешественник Иосафат Барбаро, описывая запас продовольствия татарских отрядов, уходящих от основной орды на весьма продолжительное время в степь, даёт нам представление об использовании кочевниками в своём рационе муки: «каждый татарин, ..., имеет при себе мешок 
из козлиной кожи, наполненный мукою, замешанною на меду, наподобие теста, и деревянную чашку. Тесто, выше мною описанное, размешивают небольшим количеством воды и таким образом приготовляют себе похлёбку, которой и питаются в пути» (Барбаро, 1836, c. 17).

Ещё один источник, который представляет интерес в рамках рассматриваемой темы, это сведения посла Венецианской республики Амвросия Контарини о проделанном им пути из Астрахани в Москву: «...дорога из Цитрахани до Москвы лежит ... через степь, то всякий путешественник и должен запастись нужсными припасами на всё время пути своего ... сами татары мало об этом заботятся, ... они вообще питаются одним лошадиным мясом и молоком и даже не едят хлеба, коего употребление известно только купчам, бывшим в России. По этой причине для нас крайне было затруднительно продовольствовать себя в дороге пищею. Весь наш запас состоял из небольшого количества сарачинского пшена, смешанного с кислым молоком и высушенного потом на солнще. Это кушанье называется на татарском языке тур (thur). Оно твёрдо, несколько кисловато, по уверению татар, очень питательно. Сверх означенного пшена имели мы у себя небольшой запас чесноку, луку и хорошей пшеничной муки, а также несколько сухарей, которые я добыл с большим трудом» (Контарини, 1836, c. 91-92).

\section{Примечание:}

$$
{ }^{1} \text { Аршин }=0,711 \text { м.; Вершок }=4,4 \text { см }
$$

Необходимо отметить, что муку и крупы использовали все и европейские, и восточные путешественники, а также кочевники. В то время как в сухарях (хлебе) имели потребность преимущественно европейцы и русские. Маджар, как и Азак, был центром международной транзитной торговли, куда прибывали и где формировались караваны как с востока, так и с запада, и естественно стоял вопрос об обеспечении этих караванов мукой, крупами и сухарями в достаточном количестве. С такой задачей могли справиться ремесленники, занимающиеся мукомольным производством, отвечающим потребностям рынка. Продукцию мукомолов-мельников, возможно, использовала и другая категория ремесленников, специализирующаяся на выпечке хлеба и изготовлении сухарей специально для продажи странствующим. С изменением внутриполитической ситуации в государстве менялся и жизненный уклад проживающего населения, влияющий, в том числе, и на производственные процессы, в этом случае наличие мукомольного производства может иметь признак датирующего фактора.

Данный вопрос в исследовании Золотой Орды ранее не обсуждался и имеет перспективу развития также в отношении других городов Золотой Орды, в том числе и её столичных центров, в которых такие производства пока не обнаружены.

\section{ЛИТЕРАТУРА}

Бабенко А.Н., Сергеев А.Ю. Археоботанические исследования городища Маджары // Поволжская археология. 2019. №4(30). С. 161-170 doi: 10.24852/pa2019.4.30.161.170

Барбаро И. Путешествие в Тану Иосафата Барбаро, венецианского дворянина // Библиотека иностранных писателей о России. Т. 1. СПб.: Типография III отделения Собственной Е.И.В. Канцелярии, 1836. С. 5-66. С. 17

Городиов B.A. Результаты археологических исследований на месте развалин города Маджар в 1907 году // Труды четырнадцатого археологического съезда в Чернигове, 1909 г. Т. III / Под ред. графини Уваровой. М., 1911. С. 162-208.

Контарини А. Путешествие Амвросия Контарини посла светлейшей Венецианской республики к знаменитому персидскому государю Узун-Гассану, совершенное в 1473 году // Библиотека иностранных писателей о России. Т. 1. СПб.: Типография ІІІ отделения Собственной Е.И.В. Канцелярии, С. 91-92.

Минаев A.B. Переработка зерна в Азаке в XIV в. // Археология Евразийских степей. 2018. № 4. С. $127-140$.

Недашковский Л.Ф. Хозяйство населения Золотой Орды // РА. 2009. №1 С. 91-98.

Пигарев E.M «К вопросу о земледелии на нижней Волге в золотоордынский период»// Астраханские краеведческие чтения. Вып. І. / Ред. А.А. Курапов. Астрахань: Сорокин Роман Васильевич, 2009. C. $62-65$. 
Тизенгаузен В. Сборник материалов, относящихся к истории Золотой Орды. Т. І. Арабские источники. СПб, 1884. 588 с.

Франческо Пеголотти. Руководство по торговли // Кавказ: европейские дневники XIII-XVIII веков. Вып. ІІІ. / сост. В. Аталиков. Нальчик. Из-во М. и В. Котляровых, 2010. С. 10-11.

\section{Информация об авторе:}

Обухов Юрий Дмитриевич, младший научный сотрудник научного отдела, аспирант кафедры всеобщей истории, Калмыцкий государственный университет им. Б.Б. Городовикова (г. Элиста, Россия); obuxova_t@inbox.ru

\section{REFERENCES}

Babenko, A. N., Sergeev, A. Yu. 2019. In Povolzhskaya arkheologiya (Volga River Region Archaeology) 30 (4), 161-170. doi: 10.24852/pa2019.4.30.161.170 (in Russian).

Barbaro, I. 1836. In Semenov, V. (ed.). Biblioteka inostrannykh pisatelei o Rossii (Library of Works by Foreign Writers about Russia). Saint Petersburg: Third Section of His Imperial Majesty's Own Chancery Publ., 5-66 (in Russian).

Gorodtsov, V. A. 1909. In Uvarova, P. S. (ed.). Trudy XIV arkheologicheskogo s"ezda v Chernigove (Proceedings of the Fourteenth Archaeological Congress in Chernigov, 1909). Moscow, 162-208 (in Russian).

Kontarini, A. 1836. In Semenov, V. (ed.). Biblioteka inostrannykh pisatelei o Rossii (Library of Works by Foreign Writers about Russia). Saint Petersburg: Third Section of His Imperial Majesty's Own Chancery Publ., 91-92 (in Russian).

Minaev, A. V. 2018. In Arkheologiya evraziiskikh stepei (Archaeology of Eurasian Steppes) 4. 127-140 (in Russian).

Nedashkovsky, L. F. 2006. In Rossiiskaia Arkheologiia (Russian Archaeology) (1), 91-98 (in Russian).

Pigarev, E. M. 2009. In Kurapov, A. A. (ed.). Astrakhanskie kraevedcheskie chteniia (Astrakhan Readings of Local History) I. Astrakhan: "Sorokin R.V." Publ., 62-65 (in Russian).

Plano Carpini. 1911. In Puteshestvie v vostochnye strany Plano Karpini i Rubruka (The Journey of Plano Carpini and William of Rubruk to the Eastern Parts). Saint Petersburg (in Russian).

Tiesenhausen, V. G. 1884. Sbornik materialov, otnosiashchikhsia k istorii Zolotoi Ordy. T. 1. Izvlecheniia iz sochinenii arabskikh (Collected Works Related to the History of the Golden Horde. Vol. 1. Excerpts from Arab Writings). Saint Petersburg: Typography of the Imperial Academy of Sciences (in Russian).

Francesco Balducci Pegolotti. 2010. In Atalikov, V. (comp.). Kavkaz. Evropeyskie dnevniki XIII-XVIII vekov (Caucasus. European Diaries of $13^{\text {th }}-18^{\text {th }}$ Centuries). Nalchik: “M. \& V. Kotlyarov" Publ., 10-11 (in Russian).

\section{About the Author:}

Obukhov Yuri D. Kalmyk State University. Pushkin Str., 11, Elista, 358000, Republic of Kalmykia, Russian Federation; obuxova_t@inbox.ru 